\title{
Policy Learning in Comparative Policy Analysis
}

\author{
Claire A. Dunlop*, University of Exeter, UK \\ c.a.dunlop@exeter.ac.uk
}

\author{
Claudio M. Radaelli, University College London \\ c.radaelli@ucl.ac.uk
}

\begin{abstract}
We explore how policy learning can improve comparative policy analysis by focussing on causality in learning processes. After summarising the comparative credentials of the policy learning literature, we outline a framework of four learning modes relating it to three approaches of causality: deterministic, probabilistic and set-theoretic. We then build on this to explore different approaches to causation and learning in relation to: policy change, political contexts, and, finally, the temporal and spatial dimensions of comparative policy analysis. We conclude showing how these challenges are addressed and suggest implications for further research.
\end{abstract}

\section{Keywords}

Causation, causal mechanisms, comparative policy analysis, policy change, policy learning

* corresponding author

Cite as Dunlop, C.A. and Radaelli, C.M. (2021) 'Policy Learning in Comparative Policy Analysis', Journal of Comparative Policy Analysis 


\section{Policy Learning in Comparative Policy Analysis}

We explore how policy learning can improve comparative policy analysis by focussing on causality in learning processes. After summarising the comparative credentials of the policy learning literature, we outline a framework of four learning modes relating it to three approaches of causality: deterministic, probabilistic and set-theoretic. We then build on this to explore different approaches to causation and learning in relation to: policy change, political contexts, and, finally, the temporal and spatial dimensions of comparative policy analysis. We conclude showing how these challenges are addressed and suggest implications for further research.

Causation, causal mechanisms, comparative policy analysis, policy change, policy learning 


\section{Introduction: How Comparative is the Policy Learning Literature?}

Policy learning has an impressive intellectual tradition reaching beyond the boundaries of the field of public policy. Its roots are grounded in the works of John Dewey, Harold Lasswell, Karl Deutsch, Charles Lindblom, and Herbert Simon (see Dunlop, Radaelli and Trein, 2018: ch 1). In the 1980s and 1990s, policy learning was key to the emergence of neoinstitutionalism and ideational explanations of public policy (Hall, 1993; Haas, 1990; Haas, 1992), to the solution to problem solving puzzles (Ostrom, 1990) and to the explanation of policy change (Bennett and Howlett, 1992; May, 1992).

In the last twenty years, political scientists have adopted learning as lens to address questions about policy diffusion and transfer (Dolowitz and Marsh, 1996), policy convergence (Plümper and Schneider, 2009), evidence-based policy (Cairney, 2012), a new modes of governance (Sabel and Zeitlin, 2010) and policy failure (Dunlop, 2017). Learning is also a fundamental component of the contemporary theories of the policy process, such as ideational theories of policy change (Béland, 2019), the advocacy coalitions framework (Jenkins-Smith et al, 2017) and the narrative policy framework (Shanahan et al, 2017). The explosion of the field of behavioral public policy has drawn attention to the individual-level mechanisms of learning and the micro-foundations of behavior. Bryan Jones (2017) has argued that the concept of behavioral rationality is the essential building block of public policy, re-connecting contemporary studies of learning to the behavioral tradition in organizational studies - already in 1963, Cyert and March used experiments (as well as other methods) to investigate cognitive bias and explain how organizations behave in their search for solutions, the communication of information and the formation of organizational 
expectations (Cyert and March, 1963: section 4.4). Since 2014 alone, over 200 articles have been published on the topic (Goyal and Howlett, 2018b: see section 4.3).

We know a good deal about the coverage of the recent learning literature in terms of the citation networks for influential articles and journals, research strands pursued, learning types found and units of analysis - countries, sub-national jurisdictions, and such like - and policy areas (Goyal and Howlett, 2018a, 2018b). We know much less about the state of the art in more explicitly comparative terms, even though, looking one last time back into the history of the field, Peter Hall's Governing the Economy (1986) was a classic comparative study of economic policy in France and Britain. To address this gap, we conducted our own focussed bibliographic review of 109 highly cited policy learning articles from over the past decade ${ }^{1}$. Specifically, we zoom-in on three elements we know little about: whether learning is treated as the dependent or independent variable; the comparative method in case terms; and, finally, the presence of any prescriptive policy design message.

In all (comparative) analysis we need to be clear about what exactly is being placed 'in contest' (Dodds, 2018: 6). Policy learning is more frequently the matter being explained - the explanandum $(62 \%, N=68)$ - than the explanans $(38 \%, N=41)$. This is not problematic in itself though more explication at the outset of the explanatory status of learning would safeguard against learning becoming both effect and cause in the same paper.

\footnotetext{
${ }^{1}$ We searched in the Social Science Citation Index (SSCI) on 14 February 2019 for articles with the following criteria: Topic=(policy learning) OR Topic=(organizational learning) OR Topic=(social learning) AND TOPIC=(public policy) AND Topic=(learning). The search was refined by subject areas Public Administration OR Political Science OR International Relations OR Sociology OR Urban Studies. We limited the search to articles published since 2009 to the search date - a decade - and those with six or more cites. This produced an initial sample of 761 articles. The sample was then filtered by including only those articles published in journals in the JCR's Public Administration list (47 in total). With duplicates removed, this reduced the sample of articles to 278. A further sift of the abstracts reduced our sample to 109. Papers were rejected if they used learning in colloquial terms ('what can be learned from XYZ') or learning in education policy or contained no empirics (i.e. were conceptual or prescriptive papers on policy learning).
} 
On method, there is a reassuring mix (see table 1). The single case study - which so much of policy studies is built upon - stands out at $35 \%$ of the studies examined and we have an even spread of the rest. Regarding the inclusion of the single case study, while, arguably, this is not a genuinely comparative form (Peters, 1998; Yin, 1996), we favour this broad conceptualisation because the single case study can be used to probe or test conjectures and hypotheses ${ }^{2}$. Sartori (1990: 400, footnote 5) was fond of saying that a single case study can be cast in a comparative explanatory framework or be idiosyncratic. His rule of thumb was to browse through the references of a single case study: if the bibliography contained only studies on the case being discussed, the paper was idiosyncratic and not comparative.

Table 1Case Types in the Literature

SINGLE CASE TWO CASES SMALL N (3- MEDIUM N LARGE N TOTAL

8 CASES) $\quad$ (9-30 CASES) $\quad(>31$ CASES)

\begin{tabular}{l|llllll}
\hline$N(\%)$ & $38(35 \%)$ & $21(19 \%)$ & $19(17 \%)$ & $15(14 \%)$ & $16(15 \%)$ & 109
\end{tabular}

$(100 \%)$

With over half the studies covering single or two cases, the learning literature echoes the wider comparative public policy literature. Rather than uncover patterns, comparing a limited number of cases illuminates the processes and forces that underpin distinct policy responses to common problems (Engeli and Rothmayr Allison, 2014). But, medium and large $\mathrm{N}$ studies are happening in good numbers (14\% and $15 \%$, respectively).

\footnotetext{
${ }^{2}$ See also Mackie (1995) for a trenchant defence of the single case study, and Gerring (2004) and Morlino (2018) on the difference between descriptive/configurative/atheoretical case studies and varieties of theory-informed case studies.
} 
Finally, we augment the bibliographic review material on policy learning with a search for relevance. Specifically, we are interested in the extent to which studies of policy learning are generating clear and reportable design implications. Our findings are encouraging $-30 \%$ of the articles $(\mathrm{N}=33)$ offer some prescriptive advice for institutional reforms or policy lessons.

We can see there is a good deal of activity on policy learning. Yet, the field is heterogeneous and lacks any shared language (Dunlop and Radaelli, 2013; Goyal and Howlett, 2018a, 2018b). Of course, we might have good cause to be relaxed about this. Why not let a thousand flowers bloom? Certainly, we are learning a good deal about the vast variety of learning forms and effects that exist in the social world, and the many ways in which we can research them. Perhaps learning is a special case - much of the literature would suggest authors consider it too idiosyncratic to be corralled into an ordered analytical framework (see Goyal and Howlett, 2018a: 31).

But, policy scholars increasingly regard frameworks as tools that can help us identify and tackle new analytical frontiers rather than straightjackets. Here, we recall Schlager's memorable verdict on the state of policy theories in the 1990s as characterised by: 'mountain islands of theoretical structure, intermingled with, and occasionally attached together by foothills of shared methods and concepts, and empirical work, all of which is surrounded by oceans of descriptive work not attached to any mountain of theory' (Schlager, 1997: 14). The development and refinement of master theories like the advocacy coalition framework, punctuated equilibrium theory, multiple streams approach and institutional analysis and develop has changed this landscape radically and has impacted on comparative policy analysis. The same cannot (yet) be said for policy learning. 
In this article, we explore how to advance the comparative analysis of policy learning. Our main goal is to show how policy learning can contribute to improving comparative policy analysis, especially by relating causality with a learning process. Recent theoretical developments offer a way forward. Two sets of authors in particular have pushed the agenda - Heikkila and Gerlak on collective learning (2013) and Dunlop and Radaelli's modes of learning (2013). Here, we focus on modes of learning as one framework that may have the potential to create a progressive, comparative research programme. The analytical framework is twofold. First, it is built on a systematization of policy learning literature (for the review details see Dunlop and Radaelli, 2013: 616, footnote 2). Second, it develops the modes by using theoretical expectations about learning and the concept-formation tool of explanatory typologies. However, this model does not explicitly deal with the comparative analysis. To exploit the potential of policy learning for comparative policy analysis, in the next section we address four challenges (Fontaine, 2017; Peters et al, 2018): the need for definitional clarity; the creation of a shared conceptualisation that works as a mid-range; a coherent model of causation; and, a contribution to policy design. We exert particular energy on the third concern about how policy learning connects with causality. In the following section, we situate learning and its causal logic in the context of comparative research we discuss different approaches to causation in relation to: policy change, learning contexts and time and space. We conclude by showing how the challenges are addressed and suggest implications for further research.

\section{Introducing Modes of Learning Framework}

\subsection{Defining Policy Learning}


What do we mean by policy learning? The modes approach distils the learning literature into a single and deliberately broad definition of policy learning as: 'the updating of beliefs based on lived or witnessed experiences, analysis or social interaction' (Dunlop and Radaelli, 2013: 599). Despite ontological and epistemological differences in the scholarship, this captures the core attributes of the phenomenon and is a unifying point of departure. For some, this baseline may be too broad (for example, Goyal and Howlett argue it lacks intentionality [2018]). But, recall, it is drawn from the literature and if our concepts are to travel at all we must try for encompassing starting points (Sartori, 1970).

Following Sartori (1970: 1044), we need to be clear about what we are measuring and un-pack foundational concepts to make them amenable to empirical, granular analysis. With a broad 'family' definition of learning established, we get taxonomical. Specifically, we focus on the four modes (or genus) which recur empirically: epistemic, reflexive, bargaining, and hierarchical. The typology is explanatory rather than descriptive; these four modes are produced by two conditions associated with policymaking environments: the level of tractability and certification of actors associated with an issue (figure 1). Analysing diversity demands we are conceptually clear about what is 'in' and what is 'out' of each mode of learning. The original literature review and subsequent empirical work means we can confidently distinguish each mode across a number of fundamental dimensions: metaphor of learning; predominant policy actors; knowledge use; what is learned; what the lesson is good for (see the summary in table 2). 
Figure $1 \quad$ Modes of Learning

PROBLEM TRACTABILITY

LOW

HIGH

\section{CERTIFICATION OF} ACTORS

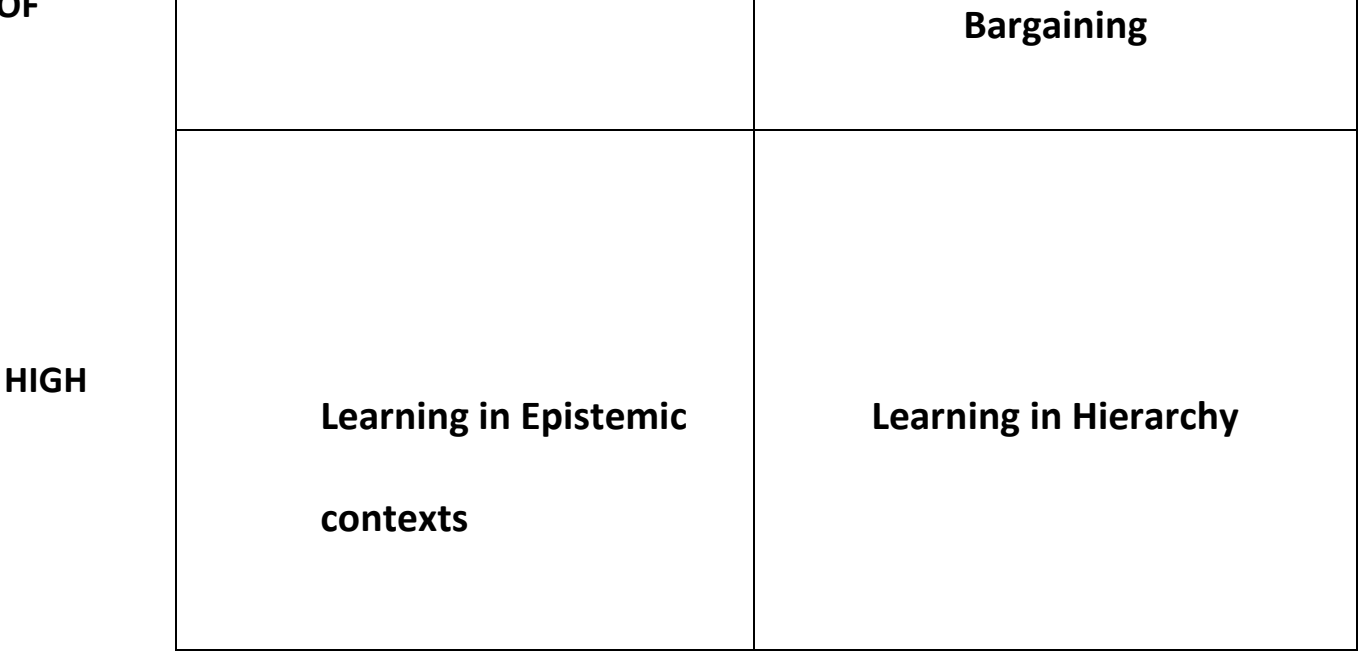

Source: adapted from Dunlop and Radaelli, 2013, figure 1: 603. 
Table $2 \quad$ Unpacking Policy Learning Modes

\begin{tabular}{|c|c|c|c|c|}
\hline $\begin{array}{l}\text { LEARNING } \\
\text { MODE }\end{array}$ & EPISTEMIC & REFLEXIVE & BARGAINING & HIERARCHICAL \\
\hline METAPHOR & teaching & dialogue & exchange & compliance \\
\hline $\begin{array}{l}\text { PREDOMINAN } \\
\text { T ACTORS }\end{array}$ & experts & citizens & interests & $\begin{array}{l}\text { courts and } \\
\text { standard setters }\end{array}$ \\
\hline $\begin{array}{l}\text { KNOWLEDGE } \\
\text { USE AS ... }\end{array}$ & instrumental & conceptual & political / symbolic & imposed \\
\hline $\begin{array}{l}\text { WHAT } \\
\text { LEARNED? }\end{array}$ & 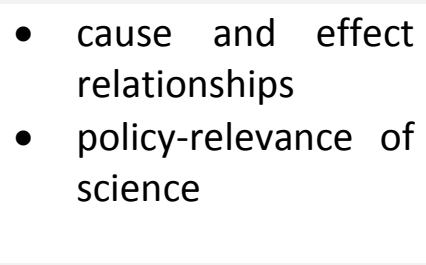 & $\begin{array}{l}\text { - } \\
\text { - } \\
\text { learning how to } \\
\text { learn (deutero) }\end{array}$ & 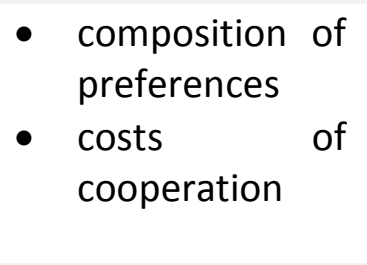 & $\begin{array}{l}\text { - } \text { scope of } \\
\text { rules } \\
\text { - } \text { significance } \\
\text { and rigidity } \\
\text { of rules }\end{array}$ \\
\hline $\begin{array}{l}\text { WHAT IS IT } \\
\text { GOOD FOR? }\end{array}$ & $\begin{array}{l}\text { - reduction of } \\
\text { uncertainty } \\
\text { - thinking through } \\
\text { the links between } \\
\text { policy means and } \\
\text { ends }\end{array}$ & $\begin{array}{l}\text { - upholding and } \\
\text { renewing } \\
\text { legitimacy } \\
\text { - conflict } \\
\text { resolution }\end{array}$ & $\begin{array}{l}\text { - exposing the } \\
\text { Pareto frontier } \\
\text { - intelligence of } \\
\text { democracy }\end{array}$ & $\begin{array}{l}\text { - } \text { monitoring } \\
\text { - } \text { sanctioning }\end{array}$ \\
\hline
\end{tabular}

\subsection{Conceptualising at the Mid-Range}

Thus, the literature review has naturally created mid-level categories that un-pack the monolith of policy learning (Sartori, 1970). And, most applications of the modes approach stop at these four which give wide comparative leverage. However, we can go lower down the level of abstraction identifying individual species within in genera. Using the method of explanatory typologies (Elman, 2005), we can decompose the two-by-two space into sixteen subtypes. This expansion is driven by education theory that treats adult learning as the product of learners' control over the objectives of learning (high or low) and the learners' control over the content and means of learning (high or low) (Mocker and Spear, 1982; Dunlop, 2009). Analytical application of these species offers more fine-grained accounts and guards against the dreaded 'conceptual stretching' (Sartori, 1970), but result is smaller case coverage. 


\subsection{Learning and Causation}

The modes of learning approach must be completed by a models of causation approach. Being explanatory, the typology identifies the conditions that determine one type of learning or another. Table 2 shows the content of what is learned and how the four types of learning perform in relation to goals such as: reducing uncertainty, handling policy conflict, exploiting the opportunity of cooperation, and delivering on compliance. This is indeed a lens put on learning as an effect of causes. The causes are the type of policy problems and the certification of actors.

Two major questions arise. First, what are the alternative models of causation available to study learning as effect of causes? Second, once we have adopted a model of causation, how does one model learning as cause of effects, and what are these effects? These questions connect with the entire special issues' focus on causation, ontology and the methodology of establishing causation (Beach and Pedersen, 2016; Fontaine, 2017).

On learning as effect of causes, let us assume that we have correctly identified the two causes of type of policy problem and certification of actors. How we approach the nature of this causal relationships depends on our ontology. Take the type of problems first. In a naturalist ontological posture (Moses and Knusten, 2012), a given problem can be seen as objectively tractable or very uncertain. Within this naturalist ontology, we can widen the typology to consider whether tractability and uncertainty are affected by contrasting values, political complexity, interdependency as well as technical knowledge of the issues that need attention (see Peters 2018 for the most important classifications of problems). However, in a world that is socially constructed (social ontology or constructivism, following Moses and Knutsen, 2012), it is the social meaning or predominant causal story that determines the 
problem types. Tractability and uncertainty depend on whether narratives and causal stories portray the problem originated by purposeful or unguided action, and whether we believe that the consequences are intended or un-intended. To illustrate, uncertainty can be seen as accidental or the intentional product of a bureaucratic machine or political logic.

The same can be said for the certification of actors. In this case, the argument for social constructivism is stronger perhaps. Certification is hardly an objective property of a system or a type of actor. It is a constellation of meanings that in a given period a community or political system shares about an organizational form - be it the Church or the Federal Reserve Bank. The choice of an ontology has implications for the methodology chosen for empirical research (Hall, 2003).

Turning now to learning as cause of effects, the literature in comparative public policy centres on policy change as the most interesting possible effect of learning. The causal logic is that individuals and organizations learn from experience and social interaction, and by drawing inferences on what they have learned these individuals and organizations will change their behaviour, leading to a change in public policy. Policy change caused by learning may or may not occur. In order to understand the causal mechanisms at work, we require deep knowledge of the case. To make the case for learning as cause one has to demonstrate that other variables have not caused change - that means to rule out rival alternative hypotheses.

This is deterministic thinking. We need to push this thinking later on by considering rival alternative hypotheses, mechanisms, and the whole chain of causation. Before we look at these three dimensions, it's useful to look at another model of causation grounded in probabilistic thinking. Pearl puts it very simply: 'The main lesson for a student of causality is that a causal model entails more than merely drawing arrows. Behind the arrows, there are 
probabilities' (Pearl, 2018: 45). Probabilistic causal strategies get at differences of degree rather than nature. Thus, the scope conditions of an outcome should be observed across a range of cases. This way we pinpoint differences in the intensity of causal effects. As we add cases, we increase theoretical leverage. There is also a third way to think about causation, that is, that learning is a difference-making condition in a combination of conditions that within a population or a single case study are associated with the outcome of policy change. This is a set-theoretic understanding of causation.

Set-theoretic or configurational causation is interesting given its implications for policy design. One of the ten principles of Bobrow's policy design (2006) is 'what are the minimum conditions for success?' If we consider learning as related to policy success, configurational causal thinking would then address this question: what are the combinations of conditions that are sufficient for success to occur in a population of cases that can be compared? This applies neatly to the needs of policy designers, who cannot find all the causes of an effect such as 'how to combat corruption', but would be very glad to know that a combination of learning how to use instruments $A, B, C$ and $D$ is sufficient for this outcome of, say, low corruption, to occur. Hence, configurational causation has its own original way of getting rid of rival alternative hypotheses. Certainly, learning about policy instruments is not the only cause of low or high corruption, but for the designer it's important to know that it may be sufficient to achieve success. Some authors however have criticised this approach for relying too heavily on deterministic thinking: 'by rejecting ideas and research tools developed in probability theory and statistics, qualitative comparative analysis takes a major step backwards' (Seawright, 2005: 24). 
For probabilistic approaches drawing on statistical methods, the comparative analysis of learning as cause of policy change is fraught with this difficulty: that when we observe change, learning may well be a plausible and empirically documented cause, but we cannot exclude other causes that are even more important than learning. In terms of models in largen studies, this may lead to bloated regression models with 20-25 control variables that try to capture the essence of omitted variables (Radaelli and Wagemann, 2018).

Explicit ex ante theorization always helps. To illustrate: learning can be conceptually separated from conditionality/imposition and mere emulation/faddish behaviour. Taking our four modes, conceptually reflexivity and epistemic learning are grounded in changes of preferences, in some cases norms too, and evidence-driven enlightenment guided by experts (epistemic) and entire communities (reflexivity). Empirically it is difficult (but not impossible) to separate hierarchical learning about how to comply from the effects of drastic impositions of sanctions, punishment and the use of violence. The bargaining mode sees learning as byproduct and un-intentional consequence of other variables, so implicitly this mode already controls for alternative rival hypotheses.

In any case, the argument for learning-as-cause must be underpinned by an explicit theorization of mechanisms (Dunlop and Radaelli, 2019). Following Pearl again, there are two expressions of 'why?':

'The first is straightforward: you see an effect, and you want to know the cause. [...] ...we observe that citrus prevents scurvy. The human mind is restless and always wants to know more. Before long we start asking the question: "Why? What is the mechanism by which citrus fruits prevent scurvy?"' (Pearl, 2018: 299) This is the other version of 'why'. 
In the context of the four modes of learning, the mechanisms of learning-as-effect-of-causes are exchange for bargaining; compliance for hierarchy; communication for reflexivity; and the identification of evidence for epistemic learning (outlined in table 2). Turning to learning-ascause-of-change, mechanisms allow us to demonstrate that the association between learning and change (or between an independent variable and learning as dependent variable) is more than correlation. The explicit theorization of mechanisms shows how exactly the cause should affect the outcome. This theorization generates observable implications. Thus, although mechanisms as such, in general, are not empirically detectable, the observable implications are. We say 'in general' because in the single case study, or in-depth comparison of two or few cases, process-tracing techniques get very close to observing causation 'in vivo'. Comparison across time and limited space (one or a few cases) generates information on how mechanisms emerge, are facilitated or hindered, and are leveraged by actors to produce an outcome. The mechanisms of social constructivism connect learning and outcomes via meanings, norms, values, and more generally ideas and 'persuasion'. The mechanisms of rational choice theory involve threats, reduction of uncertainty, exploitation of opportunities and more generally preferences and 'calculation'. In short, the logic of appropriateness versus the logic of choice. Reflexivity and epistemic learning are closer to the former logic. Bargaining and hierarchy are closer to the latter.

\subsection{Links to Policy Design}

Moving beyond causation in the analytic sense, the framework's analytical potential goes beyond stimulating understanding of decision-making and policy outcomes. Modes of learning is about design (or, in other words, prescriptive) as well as explanation. First, it is possible that decision-makers get stuck in the wrong learning mode (Dunlop and Radaelli, 
2016). To illustrate, under conditions of high uncertainty when there is no a priori knowledge of where solutions may come from, creating governance architectures based on hierarchy and bargaining is dysfunctional. This is exactly what the EU has done in the governance architecture for the euro-zone area (Dunlop and Radaelli, 2016) - and recent research indeed points to shifts towards more reflexivity (Zeitlin and Verdun, 2019). Second, and partly related to the first point, there are scope conditions that make learning in a given mode functional. For example, learning in reflexivity mode comes with scope conditions concerning the design of the venues where the search for solutions is carried out - violating these conditions deviates the learning process towards the outcome of failure (Dunlop, 2017; Dunlop, James and Radaelli, 2019).

\section{Comparative Research and the Chain of Causation}

We now go deeper into the causal nature of learning-based explanations, appraising learning modes across three key dimensions in comparative public policy (Tosun and Workman, 2017): defining public policy and change; dealing with political context and learning actors; and, understanding time and space.

\subsection{Conceptualising Policies, Learning Processes and Change}

Asking what we compare in comparative public policy analysis is not as self-evident a question as it may seem. Rather, it takes us back to foundational questions about what policy is (working out from Thomas Dye's [1975] famous refrain), Tosun and Workman (2017: 331) usefully condense the foci of different policy theories into three categories: forms, institutional arrangements, and substance. It is unusual for a policy theory to cover all three categories; tightly focussed theories like advocacy coalition framework (ACF) or punctuated 
equilibrium theory (PET) analyse one or two conceptualisations of policy. Modes of learning approach is capable of accommodating all three. To appreciate this, we need to go back briefly to some of the classic learning studies which the modes of learning approach builds on.

We start with Heclo's (1974) comparison of social policy in Britain and Sweden and, specifically, the development of unemployment insurance and pensions over the long-term. Having described inputs, processing of policy issues, outputs and feedback, Heclo concludes that the changes and differences in the form and content of social policy are part of distinct processes of collective social learning that transcends power relations. Thus, in this first monograph on policy learning, all three categories are in play. Two decades later, Peter Hall's (1993) seminal study offers a more analytically sophisticated account of how learning affects policy in the round. Examining economic policy development in Britain from 1970 to 1989, Hall links levels of change in institutional arrangements and policy content to learning that takes place around policies' forms. Conceptualising policy change in ideational terms, Hall differentiates policy instruments (first order beliefs) from their settings (second order beliefs) from more fundamental policy goals (third order). For Hall (1993), the depth and nature of change or stability in policy institutions and content are a function of changes in policy belief systems around the form of policy.

Hall takes two important steps here. First, he forces us to sharpen the unit of analysis. It is fine to consider that the form, institutions or content of policies can be a function of, or vehicles, for learning but this does not go far enough. The challenge is to conceptualise what we are learning about when we learn in policymaking. For Hall, to uncover the specific causal mechanisms that operate for and of learning, we must expose the cognitive dimension of policies. Now that we know what we are explaining - beliefs around policies (variously 
categorised) - Hall's second step is to interrogate the processes of learning that influence these beliefs. Hall's specific interest (stimulated by unanswered questions in Heclo's work) concerns the role of societal pressure and policy actors versus the power of state structures in policy learning. In terms of ontology, Hall shows how from the level of naturalist ontology we can move to the level of social constructions and ideational understandings of 'policy reality'.

Since this seminal contribution, understanding policy learning processes has become a social scientific enterprise involving the whole chain of causation.. Thinking about learningas-effect-of causes, the four modes have to be underpinned by these additional elements to aspire to the status of causal explanation: the causal logic, how knowledge is used in the policy process (to learn), the style of interaction, and, mindful of what we have just said about Hall's ideational analysis, the role of beliefs (table 3). This would allow comparative policy researchers to draw on a coherent way of distinguishing learning modes that link to distinct types of policy forms, institutional arrangements or content that dominate the same issue in different places or times.

The causal logic can be clearly identified as cognition in the epistemic mode. For hierarchy there are at least two logics at work: persuasion and threat. The compliance literature provides a long list of comparative case studies where both elements are present and at certain times, in certain institutional settings, one prevails on the other. With time, rules can acquire a taken-for-granted nature, so that individuals do not really spend time deciding about whether to follow the rule or not. In the bargaining mode, we can expect the logic to be anchored to what goes on in setting of interaction dominated by exchange. Yet we need to be more precise than pointing to the logic of exchange. Thus, we expect that the 
calculation of the payoffs or more generally the consequences of alternative courses of action, will dominate policy-relevant exchanges. It would be wrong to think that bargaining is exclusively compatible with a naturalist ontology where ideas do not matter. In an empirical study of conflict resolution, Holzinger (2004) demonstrates that bargaining and arguing are not semantic opposites. The often co-exist. Finally, in reflexivity the causal logic of learning is not just intellectual cogitation (like in the epistemic mode). We should expect a logic grounded in the capability of human beings to go beyond the dialogue of the deaf and revisit the presuppositions and arguments that inform their action.

Knowledge use is another important characteristic of the chain of causation. In hierarchy knowledge of norms and regulation is somewhat pushed down via instructions, guidance handbooks, decisions of courts, the content of mandates of public bodies and independent regulators. In bargaining knowledge is used to fuel exchanges. This would normally include knowledge about the content of the exchange as well as knowledge of the strategies that others are likely to pursue. In reflexivity knowledge use is supposed to be conceptual and shared among the participants. Under epistemic conditions, knowledge exists to enlighten or at least to reduce uncertainty.

The style of interaction does not neatly differentiate the modes of learning. However, it will be more cooperative in reflexive and epistemic modes, and more competitive in the other two. The key variable at play to further differentiate one mode from the others is the level of symmetry (table 3).

As for beliefs, they display different features in the chain of causation when we consider the four modes. The epistemic mode mobilizes scientific and professional beliefs. 
Reflexivity hinges on beliefs about what is correct, appropriate, acceptable. Bargaining revolves around beliefs about wins and losses. Hierarchy is centred on beliefs about rules.

Table 3 Pinning down the causal chain of learning-as-effect

\begin{tabular}{l|llll} 
LEARNING MODE & EPISTEMIC & REFLEXIVE & BARGAINING & HIERARCHICAL \\
\hline CAUSAL LOGIC & cognition & appropriateness & consequence & habit \\
KNOWLEDGE USE & instrumental & conceptual & political / symbolic & imposed \\
STYLE OF & cooperative & cooperative & competitive & competitive \\
INTERACTION & asymmetric & symmetric & symmetric & asymmetric \\
POLICY & beliefs around & beliefs around & beliefs around & beliefs around \\
DEVELOPMENT & technical matters & values & winners / losers & rules \\
SHAPED BY & & & &
\end{tabular}

So far, empirical studies of learning modes as the dependent variable take three forms. First, we have studies that follow the logic of the model itself. In political environments, learning is dynamic, as we have noted, the mode that dominates an issue is not permanent. Over time, exogenous forces change actor certification and / or the tractability of an issue may in ways that shift the learning space where policy debates and decisions take place. For example, an economic shock renders problematic a once stable issue decreasing its tractability or a new scientific discovery fatally destabilizes the structures of authority around an issue.

Next, through an analysis of impact assessment in the European Union (EU), political scientists have explored how certain policy instruments can trigger causal mechanisms associated with different types of policy learning (Coletti and Radaelli, 2013; Dunlop and Radaelli, 2018b). Linking policies to learning dynamics in this way echoes the work of Karl Deutsch (1963) who understood policy learning as the result of system feedbacks which themselves are the result of previous learning episodes. As a result, policy processes are dynamic, creative and adaptive. 
Finally, there are studies which illuminate the endogenous power of learning. In one account, the result of updates in knowledge actually work to against those actors who created it. In what Dunlop (2017) coins the 'irony of epistemic learning', she describes how an epistemic community was effectively disempowered as a result of the lessons it generated regarding a food safety issue in the EU. Specifically, consumer groups and industry used newly found clarity on their policy preferences to transform the issue from one of high uncertainty and authoritative experts - epistemic learning - to one where learning was a by-product of pressure group bargaining. In a similar vein, the endogenous power of learning has been seen in cases where learning occurs in dysfunctional ways (Dunlop, 2017). For example, the UK policy failure on Brexit has been analysed as the result of dysfunctional reflexive learning where the failure to achieve legitimate social consensus resulted in a learning form closer to bargained lessons (Dunlop, James and Radaelli, 2019).

Let us now consider learning as cause of policy change. This domain is ripe for development in the modes framework (and policy learning literature besides), because in comparative research the link between learning and policy change is underdeveloped (Moyson, Scholten and Weible, 2018; see Goyal and Howlett, 2018b for a strong argument of the failings of the literature in this respect). One possibility is to link each learning mode to the type of change we expect. As mentioned, policy change derived from reflexive or epistemic learning would be of the big bang variety, whereas the more routinized and predictable interactions found in bargaining and hierarchical learning modes generate small ' $c$ ' policy change. We could go further, of course, and operationalise these expectations using Hall's (1993) threefold approach to change. 
Yet, we may be moving too fast. While this extension has a logic, it may be empirically and conceptually problematic. Recall, the framework is based on the view that learning in the policy process is dynamic. While at any one time learning in an issue may be dominated by one mode and its associated policy actors, the generation of ideas and lessons is still going on in other modes.

One can reasonably expect the pre-eminent learning mode to change over time as the tractability and actor certification around an issue change or are re-shaped. What results is a more complex picture of lessons becoming layered upon each other. After all, Deutsch and Heclo suggested the learning over time resembles the rabbit zigzagging in a field (re-assessing the equilibrium from the new position) and groups trying the get out of the labyrinth from different perspectives (including the perspective that getting out of the maze is not the best solution!). So, it is logically possible to map one learning mode to one mode of policy change. Yet for the purpose of comparison across time it may not be empirically or conceptually coherent.

We should be clear about the current limits of this framework. Modes of learning was first articulated in 2013 (Dunlop and Radaelli, 2013), thus its potential to link policy learning to change is only starting to be empirically explored (for example, Daviter, 2018; Di Giulio and Vecchi, 2019; Dunlop and Radaelli, 2016; Millar et al, 2018; Polman, 2018). The results are promising, though all of the early studies follow case study or small-N comparison process tracing approaches (Beach and Pedersen, 2013). While this is a central method for theory building (Lijphart, 1971; Sartori, 1970) and is especially favoured in policy studies, it does limit comparative analysis. 
The next obvious challenge is to systematize the impacts of learning modes on policy stability or change across a larger number of cases. Further efforts to ensure variables associated with learning modes can be made equivalent in different contexts will enable this analytical ambition and facilitate the use of configurational methods. The limited results achieved in using learning as explanation of policy change may simply reflect ontological limits. In set-theoretic methods, change is the outcome of the combination of different conditions in a population. In configurational terms, the core questions are if learning appears in a string of conditions associated with change, when learning doesn't appear but is replaced by other conditions, and how important is learning in the population of cases (it may be sufficient for change to appear in 25 or 75 per cent of the cases in the population). Thinking in terms of set-theory seems a promising way to interrogate the potential of modes of learning in establishing causality in comparative research. Studies on learning informed by set-theory (some of which are comparative) include, in chronological order, Peters (1997) on cross-national learning in public management reform, Schimmelfennig (2006) testing social learning versus external incentives in processes of promotion of norms in Eastern Europe, Huntjens et al (2011) comparing eight water management systems, Bandelow et al (2019) on health policy. Maggetti and Gilardi (2016) instead use QCA in their literature review of 114 papers on mechanisms of diffusion, one of which is learning.

Finally, we observe that the causal logic linking learning and change has been theorized in many ways in comparative policy analysis, but it has rarely been corroborated by tests on its micro-foundations. In comparative policy analysis, the causal chain moves from a change of beliefs to behaviour. Behaviour changes because individuals re-organize their priors on the basis of evidence provided by experts, interaction in bargaining settings, decisions taken along the ladder of hierarchy, information and expert advice, and thick, open 
communication and dialogue. Something like a lesson is learn, something important is inferred from reality. This inferential learning is what changes policy-relevant behaviour. However, the micro-level experimental evidence does not necessarily support this chain. Under conditions of extreme surprise (like in a crisis), experimental evidence suggests that individual change behaviour first, then they receive feedback from the context in which they operate. Finally, if the feedback is positive, they gradually distil the new behaviour as 'lesson' or explanation of why they changed. In short, inferential learning comes after the change in behaviour. This alternative chain of causation was probed in the context of the crisis of the Euro by Kamkhaji and Radaelli (2017). Overall, we should not take for granted the microfoundations we adopt in theorizing about learning and policy change, but to them via comparative research with the necessary tools, including experiments.

\subsection{Political Context and Actors}

Next, we consider political context and actors (Tosun and Workman, 2017: 336-338; 334-335); where does policy learning take place and who are the main participants? Following the seminal learning studies (Hall, 1993; Heclo, 1974), the learning in modes approach is set against the backdrop of overarching institutions, cultural norms and political traditions. So while, analytically, we focus attention on the meso-level of group interactions, fundamentally this action is set against broader macro societal contexts. Heclo (1974) memorably describe this as the maze in which actors learning directed them and, over time, eventually becomes re-patterned as a result of that learning.

Where the modes of learning approach addresses cross-national comparisons of the same policy issue, analytical leverage is gained from the fact that the central dimensions of the approach - actor certification and issue tractability - are constant scope conditions which 
create four distinct learning arenas dominated by actors that fulfil the same roles, create the same knowledge types and interact according to the same logics regardless of space and time. These modes are derived from empirical realities. Their analytical job is to serve as data containers. To be sure, we are comparing the same thing, we can use indicators and criteria to ensure conceptual equivalence across space and time (Sartori, 1970). To illustrate, where epistemic learning dominates an issue, we would see expert groups at the forefront of policy action. The exact form of these experts may differ from country to country, but we can check for equivalence against our expectations (see tables 2 and 3).

Of course, we can augment what we mean by analytic equivalence, and move up or down Sartori's (1970) ladder of abstraction, depending on the issue at hand. For example, we can go back to the original modes framework which breaks each of the four learning types into the same again (for an empirical application on reflexive learning see Dunlop, 2015). Alternatively, we can narrow our mode by laying down specific criteria for the policy actors for example, we might argue to qualify as an epistemic community the expert group must have originated outside of government (evolutionary type) as opposed to having been assembled by the bureaucracy (governmental type) (for more on this distinction see Dunlop, 2010). These are theoretical and methodological choices which will be motivated by our research question. Of course, the more complex our conceptualisations of each actor and each mode, the more we complicate comparative endeavours and efforts to move beyond very small-N.

As it stands, the modes approach to context and actors lends itself to two comparative strategies. On the one hand, we can create variation by examining the same policy issue in different places. The clear boundaries of what makes each learning mode distinct, and the 
dynamics at work within each, mean that cross-national analyses can narrow down the contextual features or macro institutional arrangements that result in different learning processes and so policy choices. In a study on the initiatives to develop regulatory management indicators in the EU and the OECD, Radaelli (2018) shows that the outcome was determined by the variable of what actors had control over the goals and means of learning. Here, the difference in outcome (presence or absence of regulatory indicators) is explained by how actors in different institutional contexts go about structuring their learning.

On the other hand, we can pursue a comparative strategy which holds institutional context constant and explores policy variation over time. Here, we need to think about the material and ideational forces that shape who has authority on an issue and the supply of socially acceptable policy solutions to deal with it (i.e. our two dimensions that determine the learning mode).

\subsection{Time and Space}

A third fundamental dimension of comparative policy research concerns time. What is the appropriate time-frame for learning studies? And what is the notion of time in this field of research? Often, our decisions about time are generally pragmatic and emergent - i.e. the period of time we examine depend on the data or issue at hand. A more sophisticated approach would be to link methods decisions about time to the conception of learning at hand. Consider for example Rietig's (2018) argument that for policy learning to take place we require evidence of reflection. What are the implications of this for how long we study a policy?

Beyond research design choices, how policy learning approaches address the relationship between stability and change rests on the conception of time they assume. 
Specifically, three approaches to time can be discerned: linear; non-linear and circadian (see Marsh, 2010 for a wider discussion in relation to political analysis more generally).

First, time is frequently treated as linear. In policy theories, this idea of time is exemplified by incrementalism (Lindblom, 1959, 1965) where change is evolutionary and, in its addendum, punctuated equilibrium theory (PET) change (when it comes) is rapid and revolutionary (Jones and Baumgartner, 2005). Despite the differences in pace, the same diachronic logic of linear time is at work. We see this in some classic approaches to policy learning - most obviously Hall's (1993) work - where learning in the context of crisis triggers deep rooted changes in paradigmatic values and goal hierarchies.

In a different way, lesson-drawing (Rose, 1991) which describes the rational adoption of policy prescriptions across time and space, and policy diffusion (Meseguer, 2005; Weyland, 2005) studies that chart the travel of the same policy over time across distinct contexts are also underpinned by a linear conceptions of time and space. Of course some learning scholars would assert that such accounts that policies move from place 'A to $B$ ' and time 'T1 to $T 2$ ' can only make weak claims to being part of the policy learning genre, the tendency toward descriptive rigour means the theoretical leverage on learning produced by diffusion studies has been low (Volden, Ting and Carpenter, 2008).

Beyond this, Haas's (1992) epistemic communities framework treats as linear the learning processes triggered by expert groups. Novel insights carried in the belief systems of authoritative expert enclaves created lessons mediated by uncertainty, interpretation and institutionalisation. Over time, the learning they stimulate triggers paradigmatic shifts in policy beliefs; punctuations which may or may not lead to international policy coordination. 
Alternatively, some learning scholars reject this dualistic treatment of stability and change preferring to emphasize the contextual nature of policy. There are two major schools of thought here. First, is the interpretivist work exemplified by Richard Freeman (2006) who explores the constitutive nature of policy where change is constant and learning processes generated by policy actors' local practices (for a broad discussion of interpretivist accounts of learning in politics see Grin and Loeber, 2007). This post-structural conception treats time as non-linear, and political action contextual and contingent (in relation to policy more broadly see Bevir and Rhodes, 2003; Tonkiss, 1998).

Though not following a post-structural epistemology, this contingent, non-linear treatment of time is also evident in much of the policy transfer literature (Dolowitz and Marsh, 1996; Dolowitz, 2009; Evans, 2009). Concerned less with the spread of policies and more with the contextual mediators of learning processes across space and time, policy transfer studies tend toward thick description and process tracing, often drilling down on learning dynamics specific to individual case studies (Hadjiisky, Pal and Walker, 2017). Of course, the thick description associated with such localised and increasingly micro-level approach has been an obvious point of criticism (James and Lodge, 2003).

Finally, there are learning approaches that accommodate feedback loops in their accounts of stability and change. In this view, policy is a process of continuous change of different degrees where 'linear, irreversible processes fold back on themselves in multiple feedback cycles' (Adam, 1990: 87). In this view, policy development moves beyond a stability / change dualism to a circadian treatment of time (Bates, 2006; Marsh, 2010). The classic work on policy learning understood this sense of policy development as and through oscillation very well. Recall, in his cybernetic analysis of politics, Karl Deutsch (1963) vividly likens 
feedback in a learning system to the trajectory of a zigzagging rabbit which follows unexpected and creative paths.

Pierson's $(1995,2000)$ path dependent account examines the role (albeit limited) for policy learning in a circadian way. By focussing on the impact of events and structures that lock in policy paths and narrow learning options, Pierson reveals the multi-dimension nature of learning in policy making - change often occurs in the context of stability. More recently, the work on institutional learning and memory in policy-making (Pollitt, 2009; Stark, 2019) exposes the important of the past which can, at key moments, 'rise up' to change policy futures (Shapiro, 2016).

While the modes of learning approach can accommodate all three conceptions of time, our interest in understanding how pre-eminent modes of learning around an issue appear and change (learning as dependent variable), and how these modes impact policy development (learning as independent variable) points toward the circadian view. In circadian thinking, learning processes and policy development is both linear and cyclical. Change, and its pace, is multi-level and multi-dimensional. This is not simply a matter of saying learning that happens in one place can influence another (though it can). Rather, at any one time there can be multiple learning processes within and between different times and spaces.

Two challenges appear pertinent. The first concerns the question of whether each learning mode has its own circadian rhythm. We say this because we know from the knowledge utilisation literature that different groups of political actors often follow their own internal clock. For example, epistemic communities and courts have more rigid learning timelines - knowledge production is often plodding and unpredictable and legal processes 
can be slow and structured (if predictable) - than the learning processes of reflexive societies and interest group bargaining.

The second area ripe for development concerns the idea of the learning moment. Here, the methodological challenge is not simply demonstrating that learning has happened (with belief change underpinning policy development as the usual proxy). Rather, is it possible to identify the actual moments when learning is at its most intense? Conceptually, we have identified in another article the triggers and hindrances to learning (Dunlop and Radaelli, 2018), but empirically we know much less about the liminal spaces in which learning occurs. In anthropological studies on rites of passage, liminal spaces are expanses where people and their beliefs move from one state of being to another; the space between 'what was' and 'what happens next' (Thomassen, 2009; Turner, 1969: 94-113, 125-130). In policy learning terms this is possibly a key transition point, a period of extreme disorientation and ambiguity when old ways of thinking or learning about policy begin to crack before policy beliefs shift decisively. And so, these could be times of intense learning. Getting empirical purchase on these threshold moments will help learning scholars pin point the most potent causal mechanisms.

So far, we have placed time front and centre in our discussions. As with most political science accounts, space is treated as synonymous with place and analytically is enveloped into the temporal dimension; policy $X$ moves from country $A$ at $T 1$ to country $B$ at $T 2$. There is nothing wrong with this, but we can go much further. A more ambitious account of spatial is possible using the learning modes approach. In their notable discussion on space and change in political science, drawing on work by human geographers, Bates and Smith (2008: especially 198-199) urge us first to think beyond physical localities and territorialities to think 
in broader terms of policy spaces. The idea of the learning space is central to the modes approach; which are classified into four and the can be further narrowed into sixteen. Importantly, these spaces are not passive but are constitutive of the action itself.

With this idea of learning space, we turn to Bates and Smith's (2008) second advisory; treat time and space as interwoven. We know the impact of space can be viewed as a function of time. In the modes of learning model, contestation over who owns the learning space can be temporally constituted. The movement from one learning mode to another can be the product of exogenous changes that, over time, alter either of our scope conditions of tractability and actor certification. Alternatively, the policy action can move to a different learning space as the result of endogenous change - most obviously learning among the participants which enables them to shift the mode of learning toward themselves or to others.

But, let's be more ambitious and place space centre stage. How policies develop, the pace and nature change can be the product of the interconnections and relationships found in and between policy spaces. It matters that when we think of hierarchical learning spaces many policy actors - ordinary citizens, epistemic communities, interest groups - may play extremely limited roles or are excluded entirely. The presence and nature of interconnections within and between learning spaces then creates particular policy trajectories.

Moreover, the modes framework forces analysts to consider what is going on in other policy learning spaces which may be challenging the beliefs formed in the pre-eminent mode. Even though one learning mode may be dominant, learning will be going on in other modes simultaneously (even if this is without much influence). As well as taking a heterogenous view, we should also remember that learning can be negative as well as positive. Consider the 
scenario where, during a crisis or after a large scale policy failure, an issue falls between different learning modes creating a sort of proto-learning situation.

\section{Conclusion}

What is the potential of policy learning for comparative policy analysis? In the context of our special issue, we addressed this question by focusing on questions of ontology, causality and methodology. In the field of policy learning, the main problem is not one of ranking methods - actually a full range of methods perform well. Instead, the key issues are about definitional clarity, ontology and more generally research design.

All too often, when we think about comparative analysis, we jump to the conclusion that we are comparing policies. In this article we started from a different question, that is, what happens when we compare modes of learning? We argued that by considering different modes of policy learning we can generate granular expectations on how to approach learning as effect as well as learning as cause. This involves choices on the most suitable causal approach given the research question at hand - determinist, probabilistic or set-theoretic. Whatever the choice is, policy learning delivers more as mid-range theory. Causal identification is where we need more comparative research, especially in the microfoundations of learning and in capturing the 'learning moment'. Policy design can be usefully inspired by the comparative analysis of learning, especially in terms of the scope conditions that facilitate the emergence of one type of learning or another, the hindrances and blockages to learning processes, and finally the quality of learning. 


\section{Acknowledgements}

Previous versions of this article was presented at the Journal of Comparative Policy Analysis (JCPA) $20^{\text {th }}$ Anniversary International Workshop at the International Conference of Public Policy (ICPP), Concordia University, Montréal 26-28 June 2019 and the UK Political Studies Association annual conference Edinburgh 6-8 April 2020. We are grateful to all the participants for their criticisms and comments. We benefited from many colleagues' insights and extend particular thanks to Guillaume Fontaine, Iris Geva-May, Peter John, Evert Lindquist, B. Guy Peters, Beryl Radin and Philipp Trein. Biggest thanks must go to our special issue editors for bringing this volume together. Research for this article was supported by European Research Council project on Analysis of Learning in Regulatory Governance (ALREG) (grant 230267). The usual disclaimer applies.

\section{References}

Bandelow, N., Vogeler, C., Hornung, J., Kuhlmann, J. and Heidrich, S., 2019 Learning as necessary but not sufficient cause for major health policy change: A qualitative comparative analysis combining ACF and MSF Journal of Comparative Policy Analysis. 21(2), pp. 167-182.

Bates, S.R. and Smith, N.J., 2008 Understanding change in political science: On the need to bring space into theoretical positions and empirical analyses. Political Studies Review 6(2), pp. 191-204.

Beach, Derek and Pedersen, Rasmus Brun, 2013, Process Tracing Methods: Foundations and Guidelines (Ann Harbor, MI: University of Michigan Press). 
Beach, Derek and Pedersen, Rasmus Brun, 2016, Causal Case Study Methods (Ann Arbor, MI: University of Michigan Press).

Béland, Daniel, 2019, How Ideas and Institutions Shape the Politics of Public Policy (Cambridge, MA: Cambridge University Press).

Bennett, C.J. and Howlett, M, 1992, The lessons of learning: Reconciling theories of policy learning and policy change. Policy Sciences 25(3), pp. 275-294

Bobrow, Davis, B., 2006, Policy design: Ubiquitous, necessary and difficult, in B. Guy Peters and Jon Pierre (Eds) Handbook of Public Policy (London: Sage).

Coletti, P. and Radaelli, C.M., 2013, Economic rationales, learning, and regulatory policy instruments. Public Administration, 91(4), pp. 1056-1070.

Cyert, Richard M. and March, James G., 1963, A Behavioral Theory of the Firm (Englewood Cliffs, CA: Prentice-Hall).

Deutsch, Karl W. (1963) The Nerves of Government: Models of Political Communication and Control (London: Free Press of Glencoe)

Dodds, Anneliese, 2018, Comparative Public Policy (Basingstoke: Palgrave).

Dolowitz, D.P. and Marsh, D, 1996, Who learns what from whom: A review of the policy transfer literature. Political Studies, 44(2), pp. 343-357.

Dunlop C.A. and Radaelli, C.M., 2017, Learning in the bath-tub: The micro and macro dimensions of the causal relationship between learning and policy change. Policy and Society, 36(2), pp. 304-319. 
Dunlop, C.A., 2010, Epistemic communities and two goals of delegation: Hormone growth promoters in the European Union. Science and Public Policy 37(3), pp. 205-217.

Dunlop, C.A., 2017, Pathologies of policy learning: What are they and how do they contribute to policy failure? Policy and Politics 45(1), pp. 19-37.

Dunlop, C.A. and Radaelli, C.M., 2013, Systematizing policy learning: From monolith to dimensions. Political Studies, 61(3), pp. 599-619.

Dunlop, C.A. and Radaelli, C.M., 2016, Policy learning in the Eurozone crisis: modes, power and functionality. Policy Sciences 49(2), pp. 107-124.

Dunlop, Claire A. and Radaelli, Claudio M., 2018a, Policy learning and organizational capacity', in Edoardo Ongaro and Sandra van Thiel (Eds), The Palgrave Handbook of Public Administration and Management in Europe (Basingstoke: Palgrave).

Dunlop, C.A. and Radaelli, C.M., 2018b, Does policy learning meet the standards of a theory on the policy process? Policy Studies Journal 46(S1), pp. S48-S68.

Dunlop, C.A. and Radaelli, C.M., 2018c, The lessons of policy learning: Types, triggers, hindrances and pathologies. Policy and Politics, 46(2), pp. 255-272

Dunlop, Claire A. and Radaelli, Claudio M., 2019, Policy instruments, policy learning and politics: Impact assessment in the European Union, in Giliberto Capano, Michael Howlett and Ramesh M. (Eds) Making Policies Work: First and Second Order Mechanisms in Policy Design (Cheltenham: Edward Elgar). 
Dunlop, Claire A., Radaelli, Claudio M., and Trein, J. Philipp, 2018, Introduction: The Family Tree of Policy Learning', in Claire A. Dunlop, Claudio M. Radaelli and J. Philipp Trein (Eds) Learning in Public Policy: Analysis, Modes and Outcomes (Basingstoke: Palgrave).

Dye, Thomas R., 1975, Understanding Public Policy 2nd edn (Englewood Cliffs, NJ: PrenticeHall).

Engeli, Isabelle and Rothmayr Allison, Christine, 2014, Conceptual and methodological challenges in comparative public policy, in Isabelle Engeli and Christine Rothmayr Allison (Eds) Comparative Policy Studies Basingstoke: Palgrave

Fontaine, G., 2017, Comparative public policy, in William R. Thompson (Ed) Oxford Research Encyclopedia of Politics (Oxford: Oxford University Press).

Freeman, Richard, 2006, Learning in public policy, in Michael Moran, Martin Rein and Robert. E. Goodin (Eds), Oxford Handbook of Public Policy (Oxford: Oxford University Press), pp. $367-87$

Furlong, P. and Marsh, D., 2010, A skin, not a sweater: Ontology and epistemology in political science, Theory and Methods in Political Science (Basingstoke: Palgrave).

Gerring, J., 2004, What is a case study and what is it good for? American Political Science Review 98(2), pp. 341-354.

Goyal, N., 2017, A 'review' of policy sciences: Bibliometric analysis of authors, references, and topics during 1970-2017. Policy Sciences, 50(4), pp. 527-537. 
Goyal, N. and Howlett, M., 2018a, Framework or metaphor? Analysing the status of policy learning in the policy sciences. Journal of Asian Public Policy DOI $\underline{10.1080 / 17516234.2018 .1493768}$

Goyal, Nihit and Howlett, Michael, 2018b, Lessons Learned and Not Learned: Bibliometric Analysis of Policy Learning', in Claire A. Dunlop, Claudio M. Radaelli and J. Philipp Trein (Eds) Learning in Public Policy: Analysis, Modes and Outcomes (Basingstoke: Palgrave).

Grin, John and Loeber, Anne (2007) 'Theories of policy learning: Agency, structure and change', in Frank Fischer, Gerald J. Miller and Mara S. Sidney (Eds), Handbook of Public Policy Analysis: Theory, Politics, and Methods (Boca Raton, FL: CRC Press), pp. 201219.

Haas, Ernst B., 1990, When Knowledge is Power (Berkeley, CA: University of California Press).

Hadjiisky, Magdaléna, Pal, Leslie A. and Walker, Christopher, 2017, Public Policy Transfer (Cheltenham: Edward Elgar).

Hall, P.A., 1993, Policy paradigms, social learning and the state: The case of economic policymaking in Britain. Comparative Politics, 25(3), pp. 275-296.

Han, H., Swedlow, B. and Unger, D., 2014, Policy advocacy coalitions as causes of policy change in China? Analyzing evidence from contemporary environmental politics. Journal of Comparative Policy Analysis: Research and Practice, 16(4), pp. 313-334.

Heclo, Hugh, 1974, Modern Social Politics in Britain and Sweden: From Relief to Income Maintenance (New Haven, CT: Yale University Press). 
Heikkila, T. and Gerlak, A.K., 2013, Building a conceptual approach to collective learning: Lessons for public policy scholars. Policy Studies Journal 41(3), pp. 484-511.

Henry, A.D., Ingold, K., Nohrstedt, D. and Weible, C.M., 2014, Policy change in comparative contexts: Applying the advocacy coalition framework outside of Western Europe and North America. Journal of Comparative Policy Analysis: Research and Practice 16(4), pp. 299-312

Holzinger, K., 2004, Bargaining through arguing: An empirical analysis based on speech act theory. Political Communication 21(2), pp. 195-222.

Huntjens, P., Pahl-Wostl, C., Rihoux, B., Schlueter, M., Flachner, Z., Neto, S., Koskova, R., Dickens, C. and Nabide Kiti, I., 2011, Adaptive water management and policy learning in a changing climate: A formal comparative analysis of eight water management regimes in Europe, Africa, and Asia. Environmental Policy and Governance 21(3), pp. 145-163.

James, O. and Lodge, M., 2003, The limitations of policy transfer and lesson drawing for contemporary public policy research. Political Studies Review 1(2), pp. 179-193.

Jones, B.D., 2017, Behavioral Rationality as a Foundation for Public Policy Studies. Cognitive Systems Research 43: 63-75

Jones, Bryan, D. and Baumgartner, Frank, R., 2005, The Politics of Attention (Chicago, IL: University of Chicago Press).

Kamkhaji, J.C. and Radaelli, C.M., 2017, Crisis, learning and policy change in the European Union. Journal of European Public Policy 24(5), pp. 714-734. 
Lindblom, C.E., 1959, The science of muddling through. Public Administration, 19(2), pp. 7888.

Lindblom, Charles, E., 1965 The Intelligence of Democracy (New York, NY: The Free Press).

Maggetti, M. and Gilardi, F., 2016, Problems (and solutions) in the measurement of policy diffusion mechanisms. Journal of Public Policy, 36(1), pp. 87-107.

May, P.J., 1992, Policy learning and failure. Journal of Public Policy 12(4), pp. 331-354.

Meseguer, C., 2005, Policy learning, policy diffusion, and the making of a new order. Annals of the American Academy of Political and Social Science, 598(1), pp. 67-82.

Morlino, Leonardo, 2018, Comparison (Toronto: Barbara Budrich).

Moses, Jonathan, W. and Knutsen, Torbjørn, L., 2012, Ways of Knowing (New York, NY: Palgrave Macmillan).

Newton, Kenneth and Van Deth, Jan W., 2010, Foundations of Comparative Politics $2^{\text {nd }}$ edition, (Cambridge, MA: Cambridge University Press).

Ostrom, Elinor, 1990, Governing the Commons, (Cambridge, MA: Cambridge University Press).

Pearl, J. with Mackenzie, D., 2018, The Book of Why (New York, NY: Penguin).

Peters, B.G., 1997. Policy transfers between governments: The case of administrative reforms. West European Politics, 20(4), pp. 71-88.

Peters, B. Guy, 2013, Strategies for Comparative Research in Political Science (Basingstoke: Palgrave). 
Peters, B. Guy, 2018, Policy Problems and Policy Design (Cheltenham: Edward Elgar).

Peters, B.G., Fontaine, G. and Mendez, J-L., 2018, Substance and methods in the comparative study of policy change. Journal of Comparative Policy Analysis: Research and Practice 20(2), pp. 133-141.

Pierson, P., 2000, Increasing returns, path dependence, and the study of politics. American Political Science Review 94(2), pp. 251-267.

Radaelli, C.M., 2009, Measuring policy learning: Regulatory impact assessment in Europe. Journal of European Public Policy 16(8), pp. 1145-1164.

Radaelli, C.M., 2019, Regulatory indicators in the European Union and the OECD: Performance assessment, organizational processes, and learning. Public Policy and Administration. Early view https://doi.org/10.1177/0952076718758369

Rietig, Katharina 2018, Learning in the European Commission's renewable energy policymaking and climate governance in Claire A. Dunlop, Claudio M. Radaelli and J. Philipp Trein (Eds) Learning in Public Policy: Analysis, Modes and Outcomes (Basingstoke: Palgrave).

Rose, R., 1991, What is lesson-drawing? Journal of Public Policy 11(1), pp. 3-30.

Sabatier, P.A., 1987, Knowledge, policy-oriented learning, and policy change an advocacy coalition framework. Science Communication, 8(4), pp. 649-692.

Sabatier, P.A., 1988, An advocacy coalition framework of policy change and the role of policy oriented learning therein. Policy Sciences 21(2-3), pp. 129-168. 
Sabel, Charles, 1994, Learning by monitoring: the institutions of economic development. Neil Smelser and Richard Swedberg (Eds) Handbook of Economic Sociology, (Princeton, NJ: Princeton University Press and Russell Sage Foundation), pp. 137-165

Sabel, C.F. and Zeitlin, J., 2008, Learning from difference: The new architecture of experimentalist governance in the European Union. European Law Journal 14(3), pp. 271-327.

Sartori, G., 1970, Concept misformation in comparative politics. American Political Science Review, 64(4), pp. 1033-1053.

Sartori, G., 1990, Comparazione e metodo comparato. Rivista Italiana di Scienza Politica, 20(3), pp. 397-416.

Schimmelfennig, F., 2006, The international promotion of political norms in Eastern Europe: a Qualitative Comparative Analysis. Central and Eastern European Working Papers, Center for European Studies, Harvard, (61), pp. 1-21.

Schlager, E., 1997, A response to Kim Quaile Hill's in search of policy theory. Policy Currents 7(2), pp. 14-17.

Schneider, C. and Rohlfing, I., 2013, Combining QCA and process tracing in set-theoretic multimethod research. Sociological Methods \& Research 42(4), pp. 559-597.

Shapiro, Martin, 2016, Politics and Time (London: Polity Press).

Thomassen, B., 2009. The uses and meanings of liminality. International Political Anthropology 2(1), pp. 5-28. 
Tosun, J. and Workman, S., 2017, Struggle and triumph in fusing policy process and comparative research in Christopher M. Weible and Paul A. Sabatier (Eds) Theories of the Policy Process $4^{\text {th }}$ edn (Boulder, CO: Westview Press).

Turner, V. (1969) The Ritual Process: Structure and Anti-Structure Chicago, IL: Aline Publishing

Weible, C.M., Sabatier, P.A. and McQueen, K., 2009, Themes and variations: Taking stock of the advocacy coalition framework. Policy Studies Journal, 37(1), pp. 121-140.

Weyland, K., 2005, Theories of policy diffusion: Lessons from Latin American pension reform. World Politics 57(2), pp. 262-295.

Zeitlin, Jonathan and Verdun, Amy (eds) 2019, EU Socio-Economic Governance since the Crisis: The European Semester in Theory and Practice (London: Routledge).

Zhang, J., 2012, From Hong Kong's capitalist fundamentals to Singapore's authoritarian governance: The policy mobility of neo-liberalising Shenzhen, China. Urban Studies 49(13), pp. 2853-2871. 